\title{
Landslide Hazard Analysis Using a Multilayered Approach Based on Various Input Data Configurations
}

\author{
Ilyas Ahmad Huqqani (i) , Lea Tien Tay* (i) , Junita Mohamad-Saleh \\ School of Electrical and Electronics Engineering, Universiti Sains Malaysia, 14300, Nibong \\ Tebal, Penang, Malaysia
}

Received 20 February 2021/Revised 7 April 2021/Accepted 16 April 2021/Published 25 April 2021

\begin{abstract}
Landslide is a natural disaster that occurs mostly in hill areas. Landslide hazard mapping is used to classify the prone areas to mitigate the risk of landslide hazards. This paper aims to compare spatial landslide prediction performance using an artificial neural network (ANN) model based on different data input configurations, different numbers of hidden neurons, and two types of normalization techniques on the data set of Penang Island, Malaysia. The data set involves twelve landslide influencing factors in which five factors are in continuous values, while the remaining seven are in categorical/discrete values. These factors are considered in three different configurations, i.e., original (OR), frequency ratio (FR), and mixed-type (MT) data, which act as an input to train the ANN model separately. A significant effect on the final output is the number of hidden neurons in the hidden layer. In addition, three data configurations are processed using two different normalization methods, i.e., mean-standard deviation (Mean-SD) and Min-Max. The landslide causative data often consist of correlated information caused by overlapping of input instances. Therefore, the principal component analysis (PCA) technique is used to eliminate the correlated information. The area under the receiver of characteristics (ROC) curve, i.e., AUC is also applied to verify the produced landslide hazard maps. The best result of AUC for both Mean-SD and Min-Max with PCA schemes are $96.72 \%$ and $96.38 \%$, respectively. The results show that Mean-SD with PCA of MT data configuration yields the best validation accuracy, AUC, and lowest AIC at 100 number of hidden neurons. MT data configuration with the Mean-SD normalization and PCA scheme is more robust and stable in the MLP model's training for landslide prediction.
\end{abstract}

Keywords: Landslide; ANN; Hidden neurons; Normalization; PCA; ROC; Hazard map

\section{Introduction}

Landslides occur in many regions worldwide in the form of severe hazards (Guzzetti et al., 2012). Numerous causalities are caused by landslides, besides damage to buildings and resources. The landslide also affects the indirect cost to society, which involves a loss in production, a decline in land and buildings valuation, a loss in taxation, and other financial implications (Scaioni et al., 2014). It involves the movement of debris or soil down a slope (Cruden, 1991).

*Corresponding author.

Email address : tay@usm.my (Lea Tien Tay) 
Many researchers have studied various landslide hazardous areas of different parts of the globe. The key focus of research studies involves the inventory of landslides, the effect on the occurrences of landslides of geographical, topographical, hydrological, and environmental factors, and the involvement of triggering factors such as precipitation and earthquake. Landslide events depend on various causative factors grouped into different categories, such as geomorphology, geology, soil, land cover, and hydrological conditions (Hutchinson, 1995; Varnes, 1984).

In Malaysia, most of the landslides often occur due to heavy rainfall in the annual monsoon. It has been observed that much damage has been done in the last decade due to landslides in Malaysia (Murakami et al., 2014; Pradhan \& Lee, 2010).To mitigate and minimize the damage caused by landslides, many research projects have been carried out (Gian Quoc et al., 2018; Ya'acob et al., 2019). This is achieved by predicting and minimizing hazardous areas by proper action (Lee \& Talib, 2005; Pradhan \& Lee, 2010; Tay et al., 2014). A landslide event can not be predicted in time and space. Therefore, a landslide area is considered and categorized into various categories of possible hazards (Varnes, 1984).

The Geographical Information System (GIS) and remote sensing methods have been used to assess landslide hazards. The landslide hazard maps have been produced using a variety of mathematical techniques, ranging from conventional statistic methods such as frequency ratio (Chen et al., 2020), statistical index and weights-of-evidence (Regmi et al., 2014), and logistic regression (Lombardo \& Mai, 2018; Sun et al., 2018) to more recent advanced intelligence methods such as artificial neural network (ANN) (Shahri et al., 2019; Alkhasawneh et al., 2013; Alkhasawneh et al., 2014; Lee et al., 2020; Ortiz \& MartínezGraña, 2018). ANN is applied to many natural science applications such as speech recognition, human face recognition, classification of satellite images, and recognition of texture. The key feature of ANN is that it can process data from nominal and ordinal to linear, to ratios and any form of data distribution over any measurement scale. It also addresses qualitative factors that are usually used from different prediction and classification sources in the integrated analysis of spatial data (Kawabata \& Bandibas, 2009). Multilayer perception (MLP) is a popular feedforward artificial neural network that is mostly used for classification and prediction problems.

Many researchers have studied landslide hazard mapping using either original data or frequency ratio data (Catani et al., 2013; Liu et al., 2019), and most research works have been limited to these two data configurations of the landslide data. Therefore, this work intends to prepare three configurations of landslide causative factor values, i.e., original (OR), frequency ratio (FR), and mixed-type (MT), trained by the MLP model. The significant 
variations in the resulting landslide hazard maps are highlighted, and also insights are provided to decide which data configurations perform better. This paper aims to compare spatial landslide prediction performance using an artificial neural network (ANN) model based on different data input configurations, different numbers of hidden neurons, and two types of normalization techniques on the data set of Penang Island, Malaysia.

\section{Methods}

This research mainly focused on using various input data configurations for the MLP model to produce the landslide hazard map of Penang Island, Malaysia. Different numbers of hidden neurons are applied on MLP with the three configurations of input data for landslide analysis. Besides, the effects of normalization and the PCA scheme on the input data set are evaluated. The complete schematic diagram of landslide hazard analysis using the ANN model depicts in Figure 1.

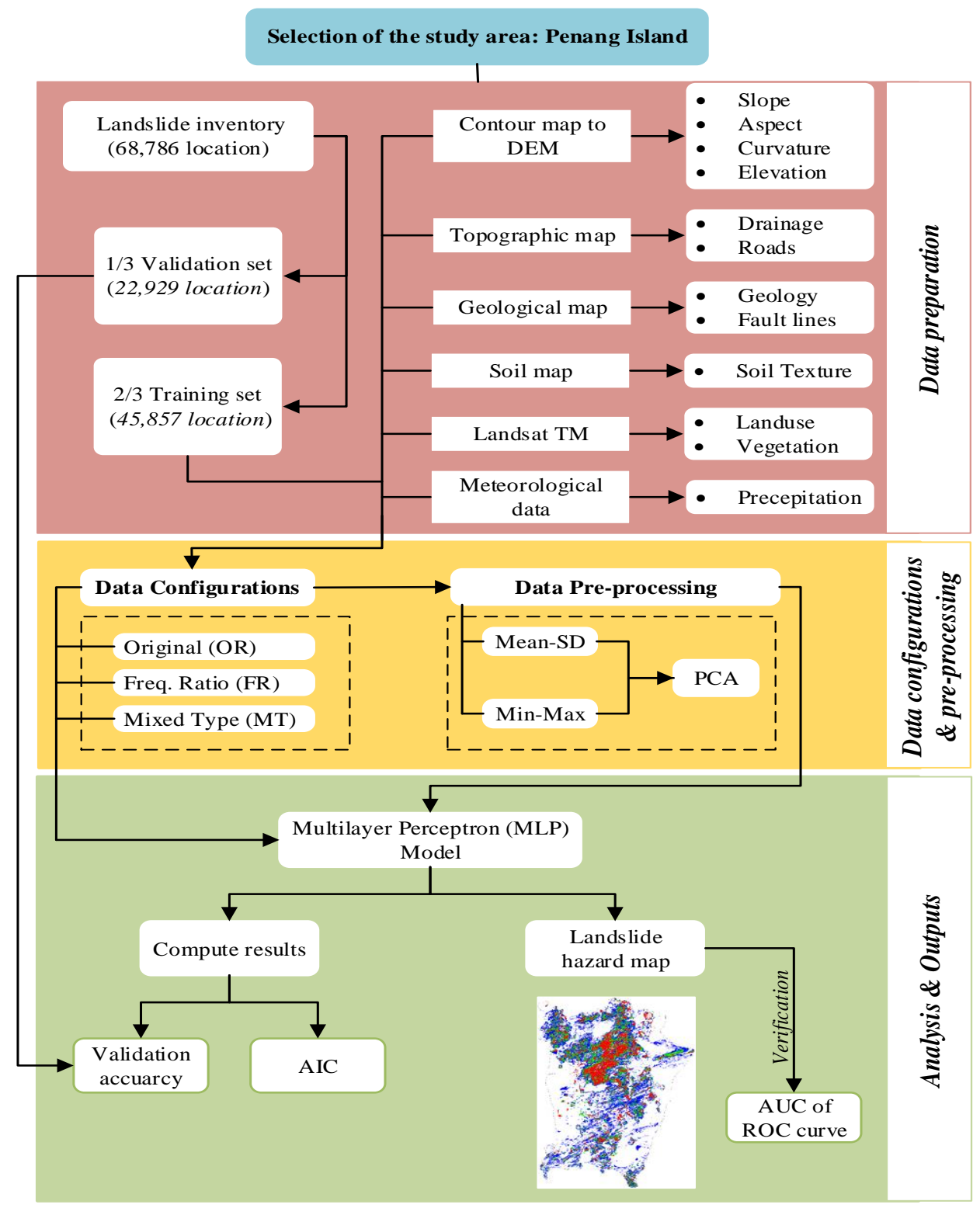

Figure 1 . The schematic diagram of the study area 


\subsection{Study Area}

Due to heavy rainfall, landslides occurred in different parts of Malaysia, and one of the most affected ones in Penang Island. Therefore, it is selected as the study area in this research work. Penang is situated on the Peninsula of Malaysia in the North-West part. Penang is bounded by two states, Kedah (North-East) and Perak (South), and Malaca and Sumatra Straits, Indonesia (West). It contains both the island and the mainland coastal strip, which is also called Wellesley Province. The study area of this research is the island of Penang. Penang island has an area of $285 \mathrm{~km} 2$. It is positioned at $5^{\circ} 15^{\prime} \mathrm{N}$ to $5^{\circ} 30^{\prime} \mathrm{N}$ latitudes and $100^{\circ} 10^{\prime} \mathrm{E}$ to $100^{\circ} 20^{\prime} \mathrm{E}$ longitudes (Huqqani et al., 2019). It is distributed into three main regions that are Greenland, forest, and urban. The slope scale ranges from $0^{\circ}$ to $87^{\circ}$, and the elevation of the terrain is 0 to $820 \mathrm{~m}$ above sea level. Penang Island's temperature ranges from $29^{\circ} \mathrm{C}$ to $32^{\circ} \mathrm{C}$. The approximate amount of rainfall ranges from $2254 \mathrm{~mm}$ to $2903 \mathrm{~mm}$ yearly. Forests and fruit plantations are the primary sources of vegetation on Penang Island. Fault lines also impact this island. Such lines occur from North to South in the middle of the island. The location map of the study area is shown in Figure 2.

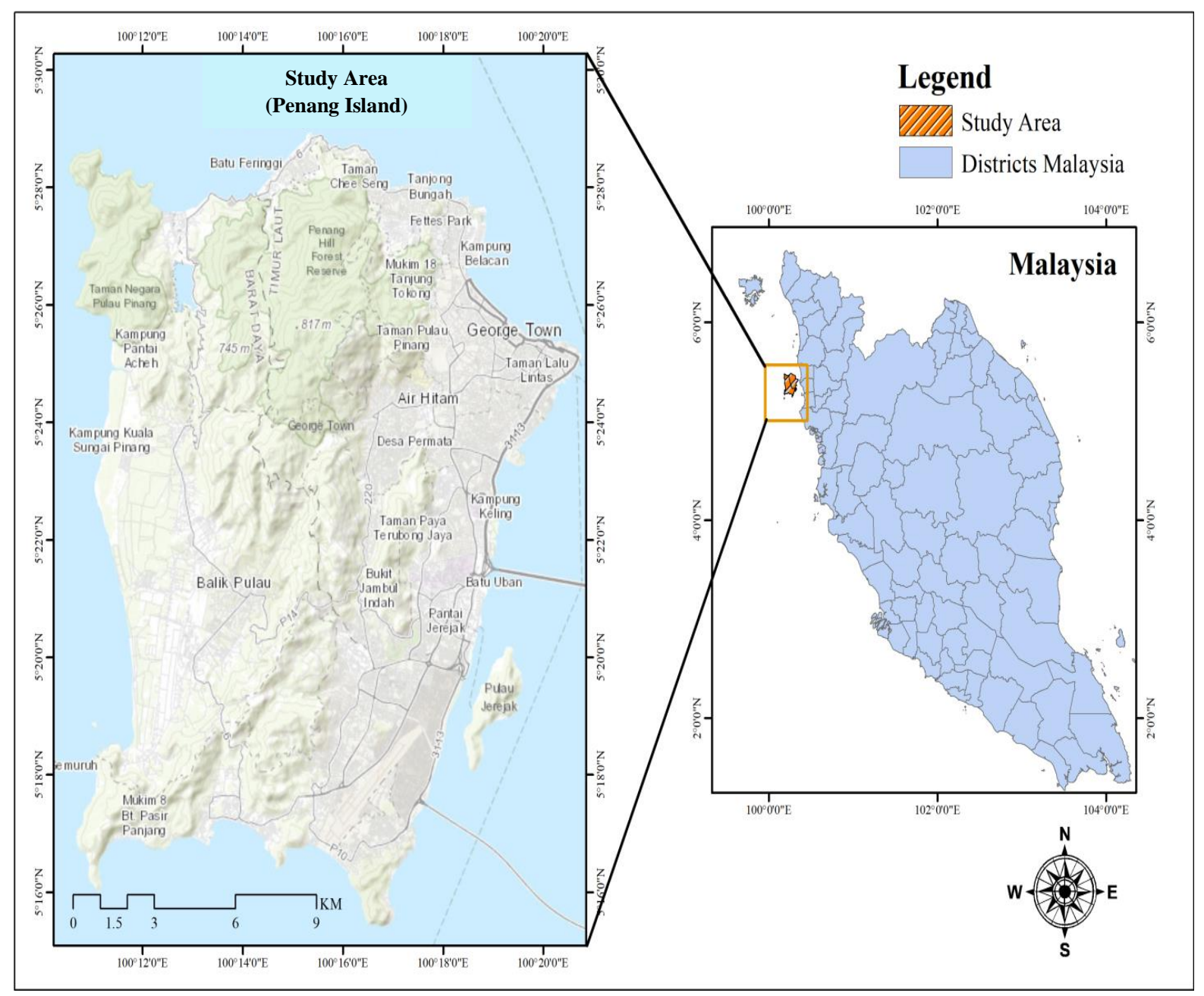

Figure 2. The location map of the study area 


\subsection{Data Preparation}

The study area's data collection is acquired using remote sensing methods and the Geographical Information System (GIS). Several images of Penang Island have been collected from various government organizations in Malaysia, such as the Department of Irrigation and Drainage (DID), the Malaysian Department of Meteorology, the Department of Agriculture (DOA), and the Department of Minerals and Geo-Science (JMG). Penang Island landslide occurrence points are also collected and transformed into a geographic dataset of $5 \mathrm{~m}$ resolution. The island's hilly topography is in the middle of the island and is considered the most landslide-prone area. The landslide types comprise shallow slides of rotational debris and flows of debris. To understand the primary cause of landslides, the relationship of triggering factors with slope failure and the identification of instability should be carried out (Guzzetti et al., 1999). Before applying the ANN model, the data sets of landslide influencing features are collected and converted into the spatial data set. Twelve landslide influencing factors are used to train the MLP model. The topographic database is used to extract a digital elevation model (DEM) of $5 \mathrm{~m}$ resolutions. DEM elevation is used to calculate the slope's angle, the aspect of the slope, and the curvature of the slope. The distances from the road and drainage are determined using the profiles of road and drainage. For these line features, the buffer zones should be prepared as $50 \mathrm{~m}$ (Van Westen et al., 2003; Westen, 1993). The distances from the fault lines are split into separations of $100 \mathrm{~m}$. Six types of distinct Penang Island granites are covered in the geology profile. The island's soil texture consists of six different kinds of soils. Precipitation is the natural triggering factor for landslides on the island. The soil dampens, the debris and rocks are washed away due to heavy rainfall. Because of limited rain measurement stations on the island, the inverse weight distance interpolation method is used to generate the precipitation profile. The landslide influencing profiles/maps are generated using the ArcGIS software and shown in Figure 3.

\subsection{Data Set Configurations}

The landslide data set consists of twelve landslide influencing factors, with five factors having continuous values, while the other seven have categorical/discrete values. The categorical data types are qualitative attributes treated as distinct symbols or just the name of the attributes. These twelve factors are arranged in three configurations. The first type of input data is Original (OR) data, which involves continuous and discrete/categorical values. The second type of data is frequency ratio data, and the third one is mixed-type data. The Frequency Ratio (FR) data is calculated from the OR data for all the twelve factors based on Eq. (1): 


$$
F R_{a b}=\frac{A_{a b}^{*}}{A_{a b}} \times \frac{A}{A^{*}}
$$

where $F R$ indicates the frequency ratio of every factor, $A_{a b}^{*}$ is the area of landslides occurrence of class $a$ factor $b, A_{a b}$ denotes the area of class $a$ of factor $\mathrm{b}, A^{*}$ and $A$ are the total areas of the landslides occurrence and study area maps, respectively.

The mixed-type (MT) data is the combination of the OR and FR data where FR factors values are used to replace those factors which are categorical/discrete. Categorical values are replaced because they are just the representation or the name of a certain factor and do not carry any numerical meaning. The factors in continuous values remain the same as in OR data.

(a) Elevation (m)

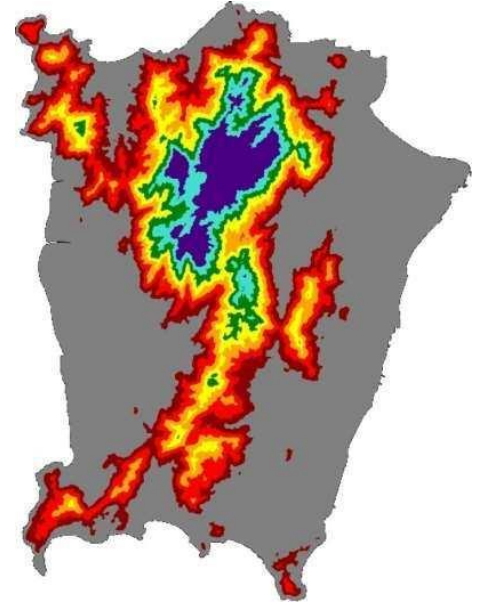

(d) Slope aspect

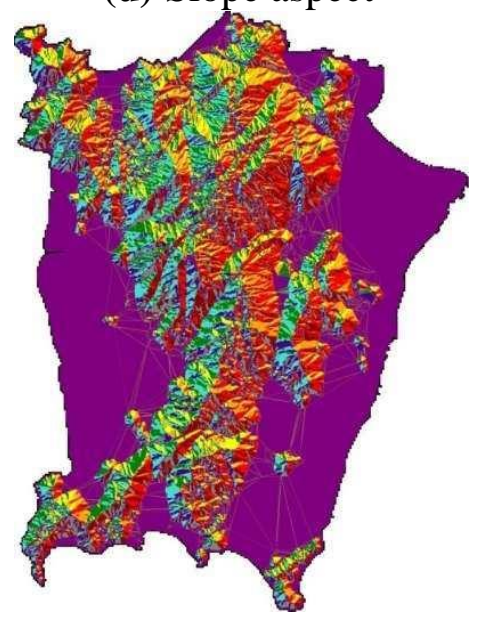

(b) Slope angle (deg.)

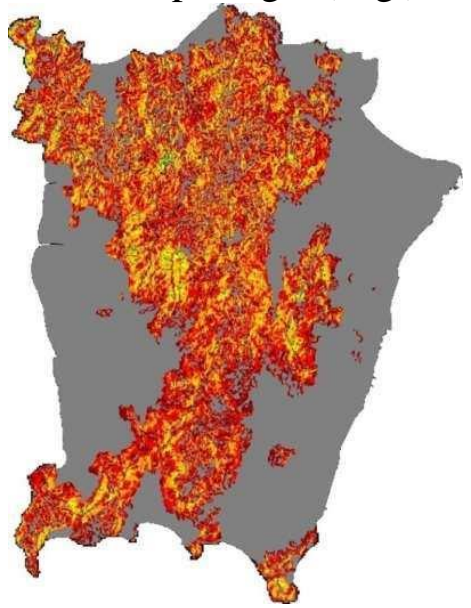

(e) Distance from drainage (m)

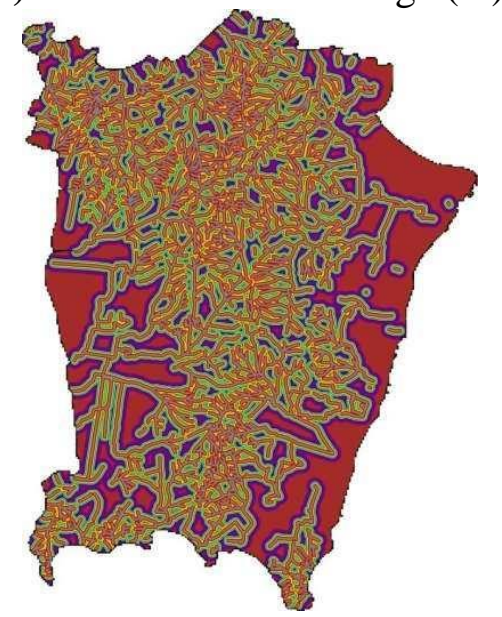

(c) Curvature

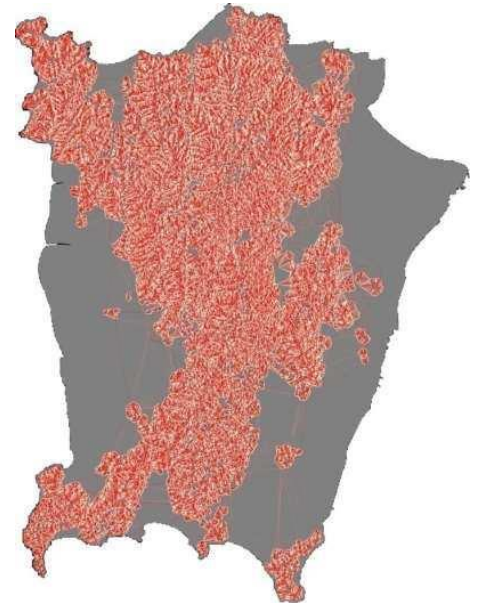

(f) Distance from road (m)

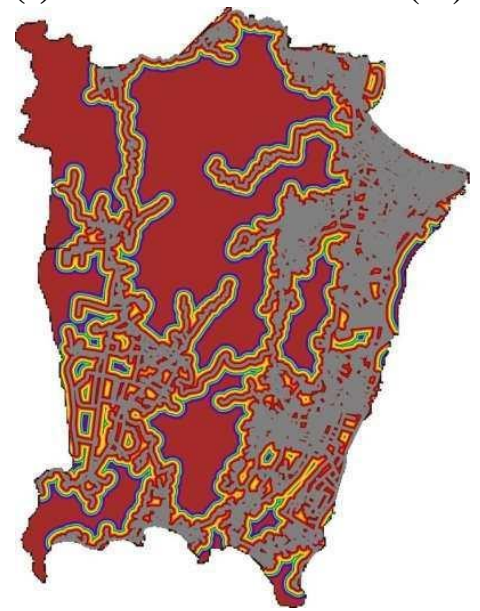


Ilyas Ahmad Huqqani et al. / Geosfera Indonesia 6 (1), 2021, 20-39
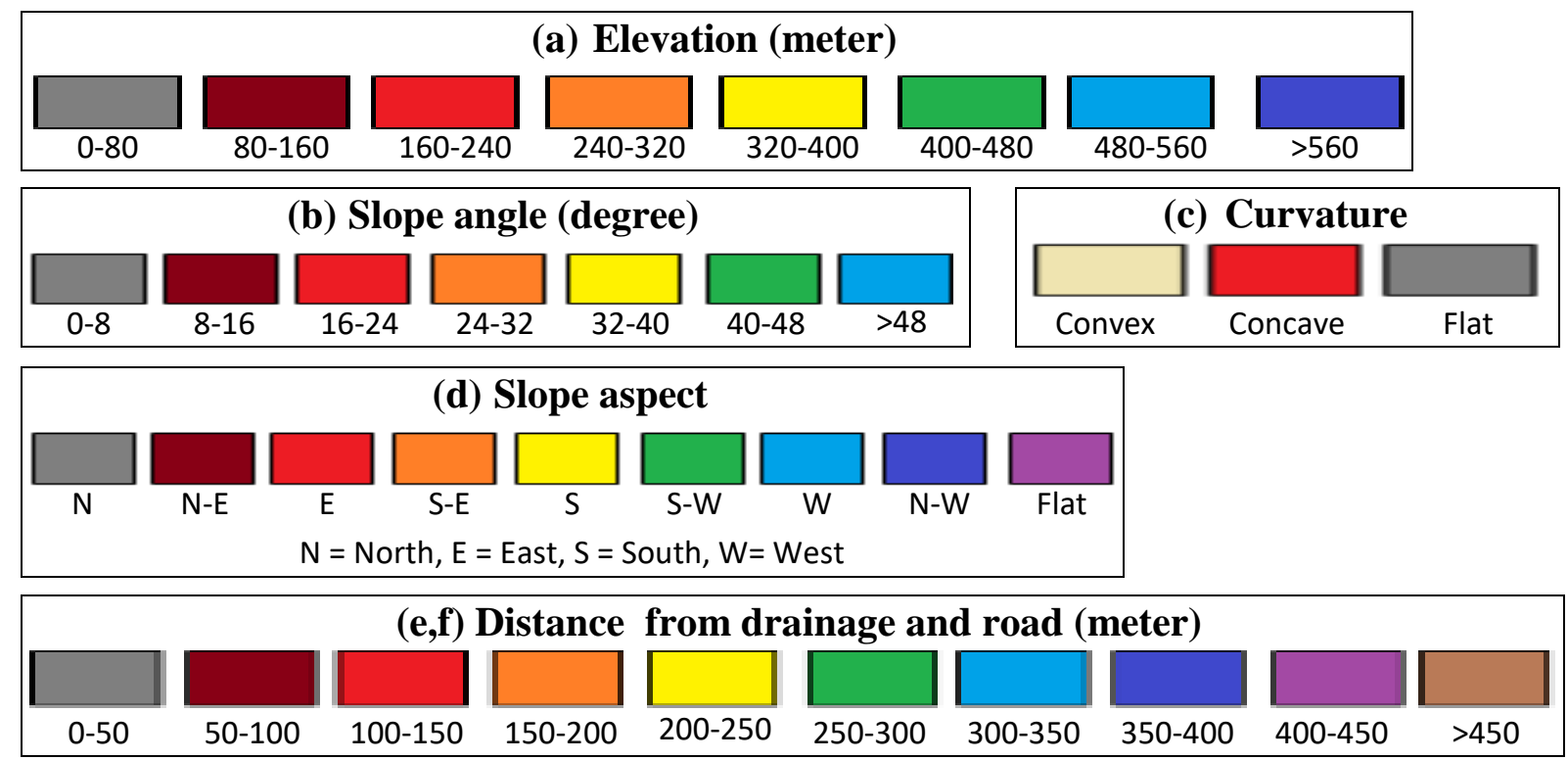

(g) Distance from fault lines (m)

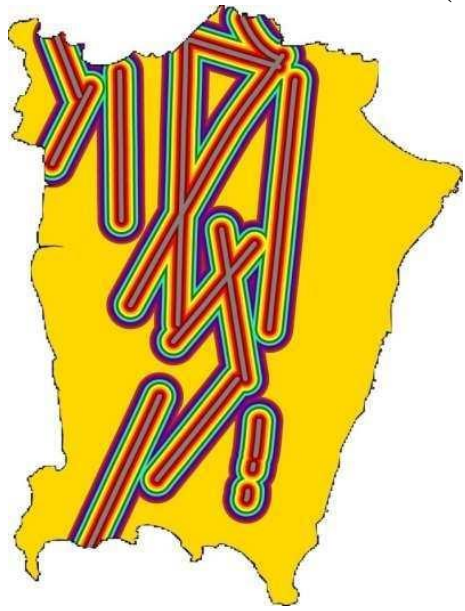

(j) Vegetation cover
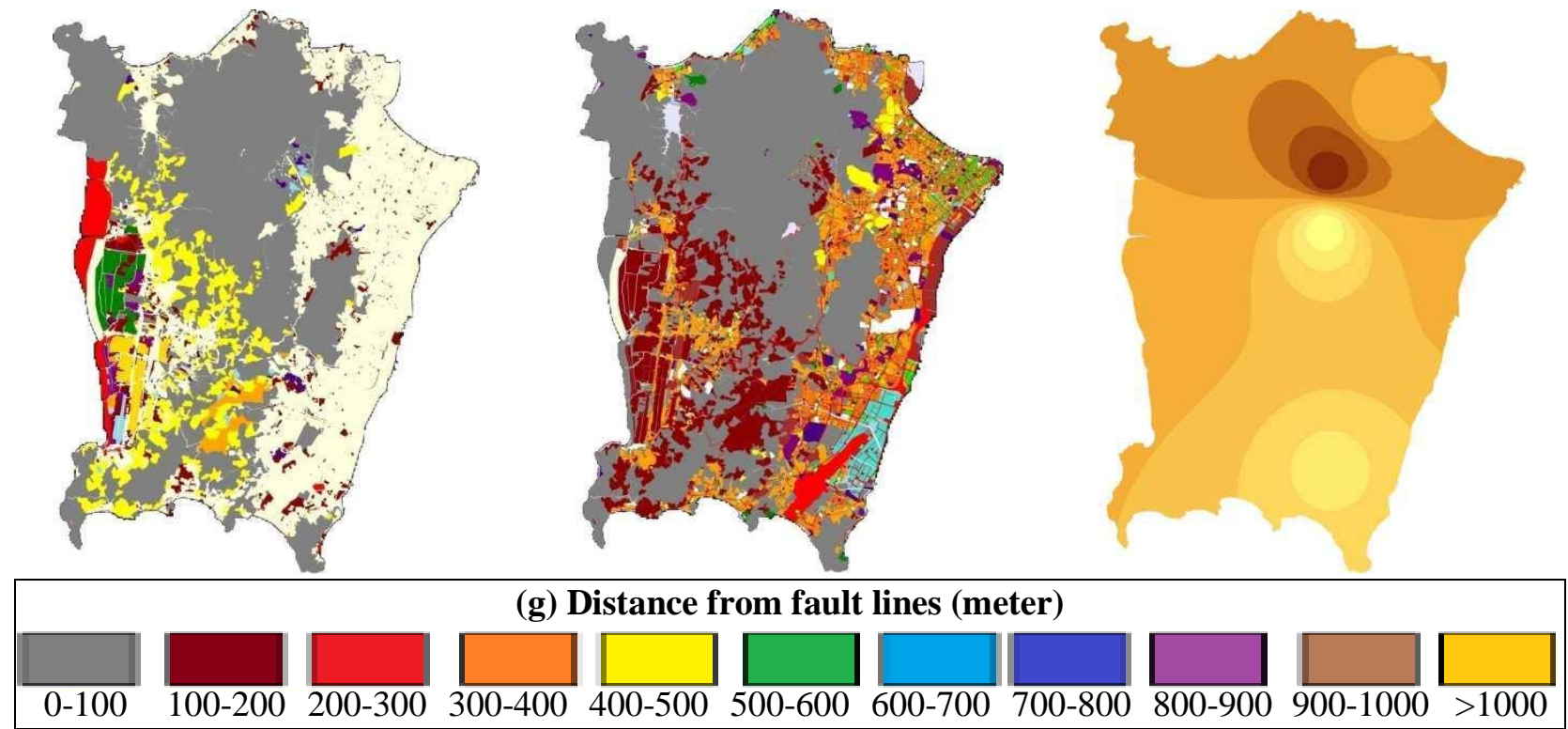

(h) Soil texture

Sand

Sandy clay

Sandy clay loam (h) Soil texture

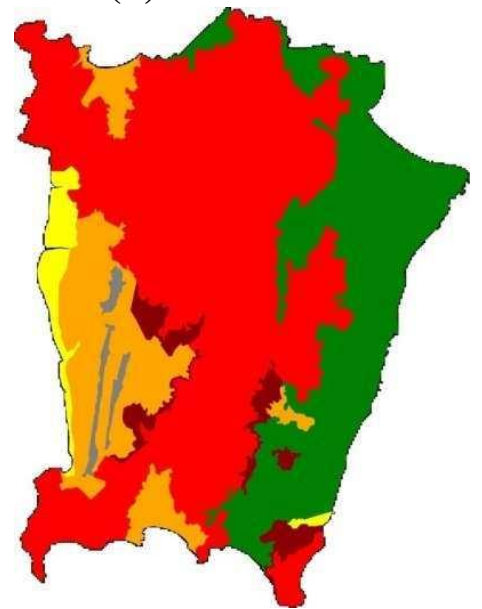

(k) Land use cover

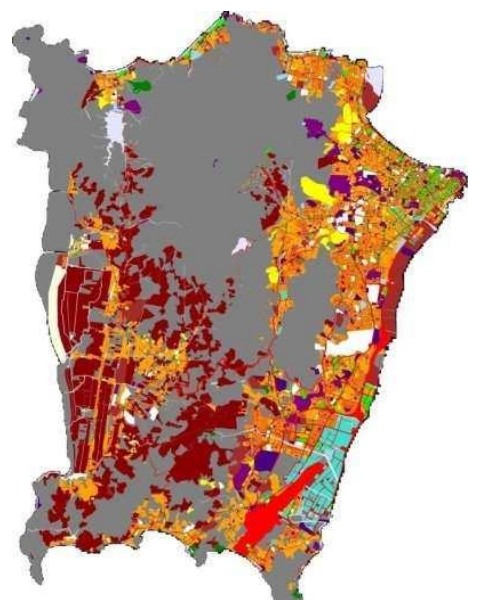

(i) Geology

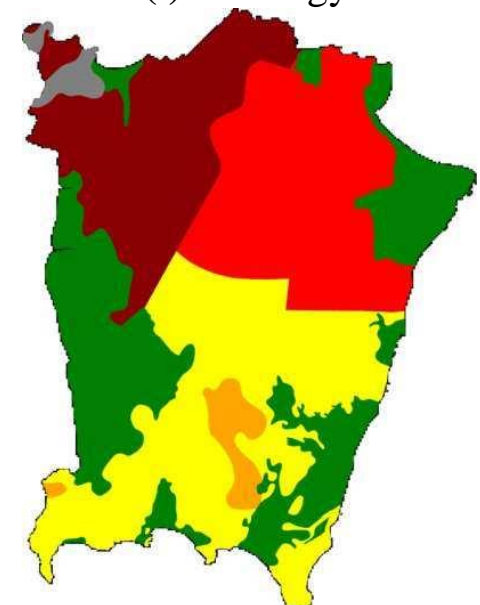

(l) Precipitation $(\mathrm{cm})$

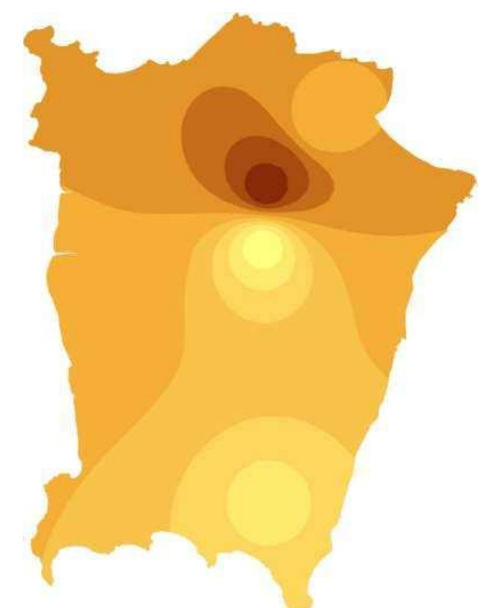

(g) Distance from fault lines (meter)

\begin{tabular}{|c|c|c|}
\hline (i) Geology & \multicolumn{2}{|c|}{ (j) Vegetation cover } \\
\hline Muka head microgranite & Forest, plant & Vegetable farm \\
\hline Feringgi granite & Bush & Coconut \\
\hline Tanjung bunga granite & Swamp & Pineapple \\
\hline
\end{tabular}




\begin{tabular}{|c|c|c|c|}
\hline Sandy loam & \multirow{3}{*}{$\begin{array}{l}\text { Sungai ara granite } \\
\text { Batu maung granite } \\
\text { Clay, sand, granite }\end{array}$} & \multirow{4}{*}{$\begin{array}{l}\text { Mixed farm } \\
\text { Fruit farm } \\
\text { Oil palm } \\
\text { Sugarcane }\end{array}$} & Paddy \\
\hline Silty clay & & & Rubber \\
\hline Urban land & & & Others \\
\hline \multicolumn{2}{|c|}{ (k) Land use cover } & & None \\
\hline Forest, bush, swamp & Plains, hills & \multicolumn{2}{|c|}{ (l) Precipitation (cm) } \\
\hline Vegetation & Buildings & $2254-2319$ & $2536-2595$ \\
\hline Transport & Religious area & $2320-2379$ & $2596-2661$ \\
\hline Settlement & Business & $2380-2433$ & $2662-2733$ \\
\hline Cemetery & Sea, lake, river & $2434-2481$ & $2734-2903$ \\
\hline Mining & Public utility & 2482-2535 & \\
\hline Industry & Livestock & & \\
\hline Government institution & Education & & \\
\hline Public facility & & & \\
\hline
\end{tabular}

Figure 3. The profiles/maps of landslide influencing features

\subsection{Data set pre-processing}

The normalization technique is employed at the pre-processing stage to transform the data set from the existing range into a new range. The input data set is normalized before applying PCA and feeding it into the MLP model. It guarantees the stable convergence of the MLP model's weights and biases. Two types of normalization methods, i.e., mean-standard deviation (Mean-SD) (de Souto et al., 2008; Kotsiantis et al., 2006) and Min-Max (Husin et al., 2008; Kaur et al., 2016), are applied on all three data set configurations separately. Different normalization techniques behave uniquely on the same data set. The purpose of applying two different normalization approaches is to identify the most appropriate technique for better results.

Mean-SD normalization: It gives the standardized values based on the mean $(\bar{X})$ and standard deviation $(\sigma)$ of the data set $(X)$. The mathematical expression of Mean-SD is given in Eq. (2).

$$
X_{\text {norm }}=\frac{X_{k}-\bar{X}}{\sigma}
$$

where $X_{k}$ and $X_{n o r m}$ denote the $k^{\text {th }}$ value of attribute $X$ and the normalized values of $k^{\text {th }}$ value, respectively.

Min-Max normalization: It is a linear alteration of the original data set $(X)$ based on the minimum value $\left(X_{\min }\right)$ and maximum value $\left(X_{\max }\right)$ of the data. Eq. (3) demonstrates the relationship of Min-Max normalization.

$$
X_{\text {norm }}=\frac{X_{k}-X_{\min }}{X_{\max }-X_{\min }}
$$


where $X_{k}$ and $X_{\text {norm }}$ denote the $k^{\text {th }}$ value of attribute $X$ and the normalized values of $k^{\text {th }}$ value, respectively.

Principal component analysis (PCA): The landslide data is in large dimensions and comprises multiple factors. Some of these factors may be correlated with each other and overlapping. It may degrade the performance of the MLP model during the training phase. The principal component analysis (PCA) is applied to the normalized data set to overcome the performance degradation issue. The main goal of PCA is to project the original data onto the new data space, which generate the principal components in descending order of the variance. The first principal component represents the maximum variance in the data, while the second principal component denotes the maximum of the remaining amount of variance and the cycle goes on. These components are orthogonal with each other and uncorrelated.

\subsection{Artificial neural network (ANN) model}

The ANN, inspired by biological neural networks, is the most efficient and powerful intelligence learning model. ANN can follow the variation in the hidden layer during the learning process, and it is used in various applications because of its good non-linear mapping ability, high learning accuracy, and robustness (Sheela \& Deepa, 2013). There are two types of ANN, i.e., feedforward and feedback. The MLP model is the most common type of feedforward ANN, which is used for the classification and forecasting of complex problems. There are three adjoining layers in the basic architecture of MLP, i.e., input layer, hidden layer, and output layer (Haykin, 1994), as illustrated in Figure 4.

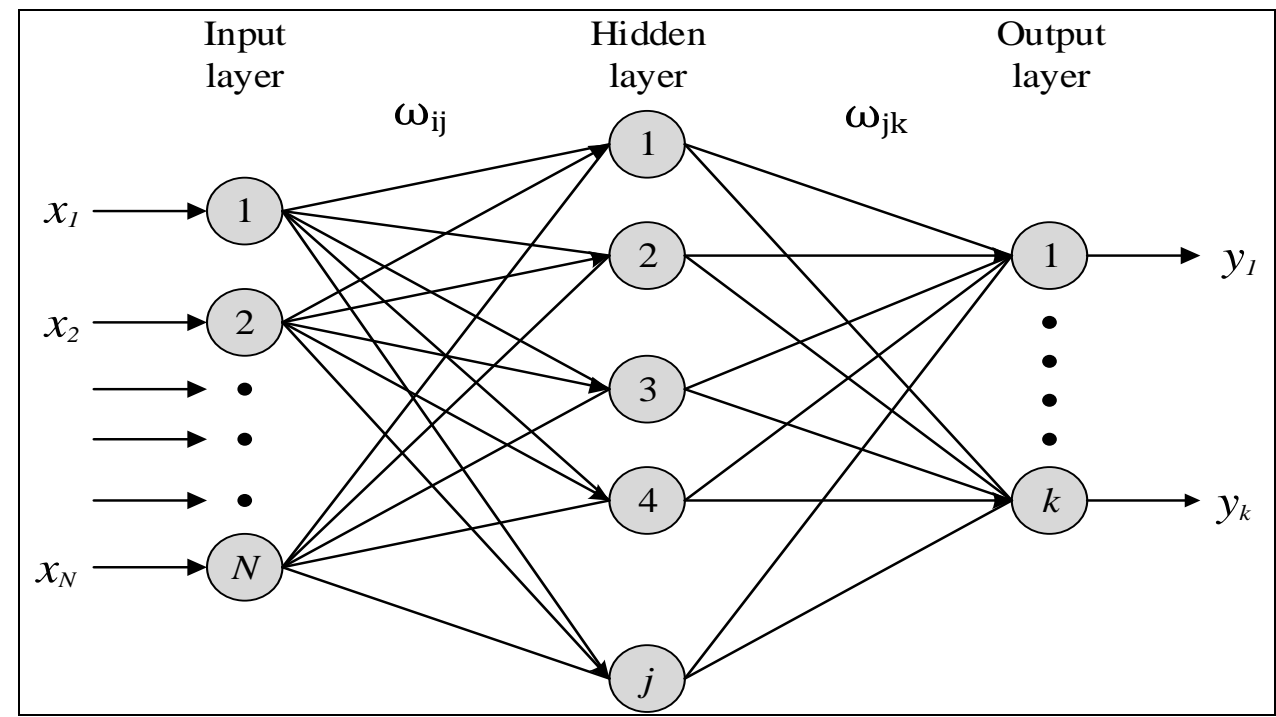

Figure 4. The architecture of MLP model 
These layers have independent processing units named neurons. The input layer's neurons are linked to successive layer's neurons of the MLP model through weights. During the backpropagation learning process, these weights are adjusted, and the MLP model establishes a mapping function between inputs and outputs (Garrett, 1994). The input neurons $x_{1}, x_{2}, \ldots, x_{N}$ take the data from the external environment and pass the data through the input weights, $\omega_{11}, \omega_{21}, \ldots, \omega_{i j}$ to the hidden neurons in the learning process. The hidden neurons' values are mapped by weights $\left(\omega_{j k}\right)$ and function as input values to the output layer for all neurons. The predicted output $y_{1}, y_{2}, \ldots, y_{k}$ values are achieved at output neurons. The error of the MLP model is measured by taking the difference between predicted output and actual input. The training process is halted when an acceptable small error is attained. In MLP, landslides influencing factors are considered independent variables at the input nodes, whereas the hidden layer processes the input data's weightage computation. There are two stages in MLP neural networks, i.e., the training stage and the classification stage. In the training stage, the internal weights are adjusted. The backpropagation algorithm is used in the MLP neural network model until minimum error is reached between the original and desired output values. After completing training, the network is ready to be utilized as a feedforward structure that produces a classification for the overall data (Paola \& Schowengerdt, 1995).

This study investigates different input data configurations with pre-processing on the MLP model for landslide prediction. The total landslide occurrences in the study area include 382 locations with 68,786 pixels. For the MLP model, the total samples 137,572 are extracted from the data set. Half of them $(68,786)$ is the landslide samples and denoted by ' 1 ', and the remaining samples $(68,786)$ are the non-landslide occurrence represented by ' 0 '. Those samples are taken from each data configuration after the pre-processing stage, and they are divided into three subsets, $50 \%$ for training, $25 \%$ for validation, and $25 \%$ for verification, respectively. Every subset is randomly selected, with the ratio remains the same. By increasing the number of hidden neurons from 5 to 120 with an increased interval of 5 , the MLP model is trained five times for each data configuration with different random initial weights and biases. The highest validation accuracy model is chosen from the five repetitions at a given number of hidden neurons. The MLP model is also trained with cross-validating the training and validation samples to avoid overfitting. The learning rate is set to 0.001 , and the initial weights are selected randomly. The maximum epochs are set to 1000 , the momentum parameter is 0.9 , and 0.01 means squared error (MSE) value is used as stopping criteria. 
One of the MLP model's main challenges is to estimate the number of neurons in the hidden layer of MLP structure because there is no analytical method to identify the optimal structure in advance. Therefore, Akaike Information Criterion (AIC) is used to determine the number of hidden neurons (Akaike, 1974). AIC is an asymptotically unbiased estimator of insample prediction error used to assess the goodness of the mathematical model. Many other models can be ranked according to their AIC, with the best for a data set being the one with the lowest AIC. The goodness of a model's parameters can be determined by the expected log-likelihood (Cousineau \& Allan, 2015; Panchal et al., 2010). The AIC's mathematical expression is based on the likelihood function and free parameters of the model $(p)$ as shown in Eq. (4). The likelihood function is defined in terms of sum of the squared error (SSE). For a set of data, $n$ is the number of data points (observations), and SSE is the sum of the squared errors of the data points. Eq. (4) is simplified to Eq. (5).

$$
\begin{aligned}
& A I C=-2 \ln (\text { likelihood })+2 p \\
& A I C=n \ln \left(\frac{S S E}{n}\right)+2 p
\end{aligned}
$$

The important metric for the ANN model evaluation is the validation accuracies. These accuracies are computed by using the Eq. (6), which is the ratio between correct outputs to the total number of data samples. The correct outputs are the sum of true positive $\left(T_{P}\right)$ and true negative $\left(T_{N}\right)$, that the MLP model classified successfully. While the total data sample number is the sum of correct outputs and incorrect outputs (false positive, $F_{P}$ and false negative, $\left.F_{N}\right)$.

$$
\text { Accuracy }=\frac{T_{P}+T_{N}}{T_{P}+F_{P}+F_{N}+T_{N}}
$$

Another metric for verification of the model is Receiver Operating Characteristic (ROC). The entire Penang Island data set of the three data configurations after normalization and followed by the PCA technique are applied on the trained MLP model to compute the accuracy, i.e., area under the curve (AUC) of Receiver Operating Characteristic (ROC) of landslide hazard maps separately. For validating the hazard maps, there are two assumptions taken, i.e., on geographic data and triggering factors. The landslides are associated with geographic data of landslide causative factors such as topography elevation and slope angle. The triggering factors, like precipitation, influence future landslides(Chung \& Fabbri, 1999). The ROC is to group the landslide hazard index (LHI) from the trained MLP model in descending order. The LHI indexes are split into one hundred sub-levels on the y-axis with $1 \%$ gaps on the x-axis (Pradhan \& Lee, 2010). The ROC curve indicates the efficiency of the 
methods, and the accuracy is achieved by measuring the area under the curve (Begueria, 2006; Chung \& Fabbri, 1999). In this study, the MLP model is carried out using the three input data configurations, with and without pre-processing. The MLP model is implemented in MATLAB on a machine with the specification Core i7 $3.40 \mathrm{GHz}$ processor and installed RAM of $16 \mathrm{~GB}$.

\section{Results and Discussion}

In this study, different numbers of hidden neurons are applied on MLP with the three configurations of input data. The implementation of MLP is carried out with and without preprocessing of normalization and the PCA scheme. AIC and ROC are used to evaluate the performance of the MLP.

Figure 5 shows the accuracies of validation and AIC during the MLP model's learning phase at different numbers of hidden neurons of three input data configurations without preprocessing. If the number of hidden neurons increases, the validation accuracies of all three data configurations also increase. The AIC values also decrease as the number of hidden neurons increases. The AIC comparison shows the lowest value for OR and FR data configuration is at 105 hidden neuron numbers, whereas the MT data configuration has the lowest AIC value at 100 hidden neuron numbers. The validation accuracy of OR and FR data configurations reaches maximum at 105 hidden neurons, which are $93.55 \%$ and $91.00 \%$ respectively, while the validation accuracy of MT data configuration is higher, i.e., $94.21 \%$, at 100 hidden neurons.

The MT data configuration performs better than the other two data configurations because all MT data variables are either continuous data or frequency ratio, which gives a better range of variation. It also provides a better and meaningful representation of landslide data. Contrary to FR data configuration, all variables are completely in frequency ratios which have minor variations. That is why FR data has lower validation accuracies. All variables of OR data configuration are a mixture of continuous and categorical/discrete values. However, this data has relatively more variations and produces higher validation accuracy than FR data configuration but slightly lower validation accuracy than MT data configuration. Furthermore, all three data configurations are processed through preprocessing, i.e., normalizations followed by the PCA technique before feeding into the MLP model to improve accuracy and eventually produce the hazard maps. 


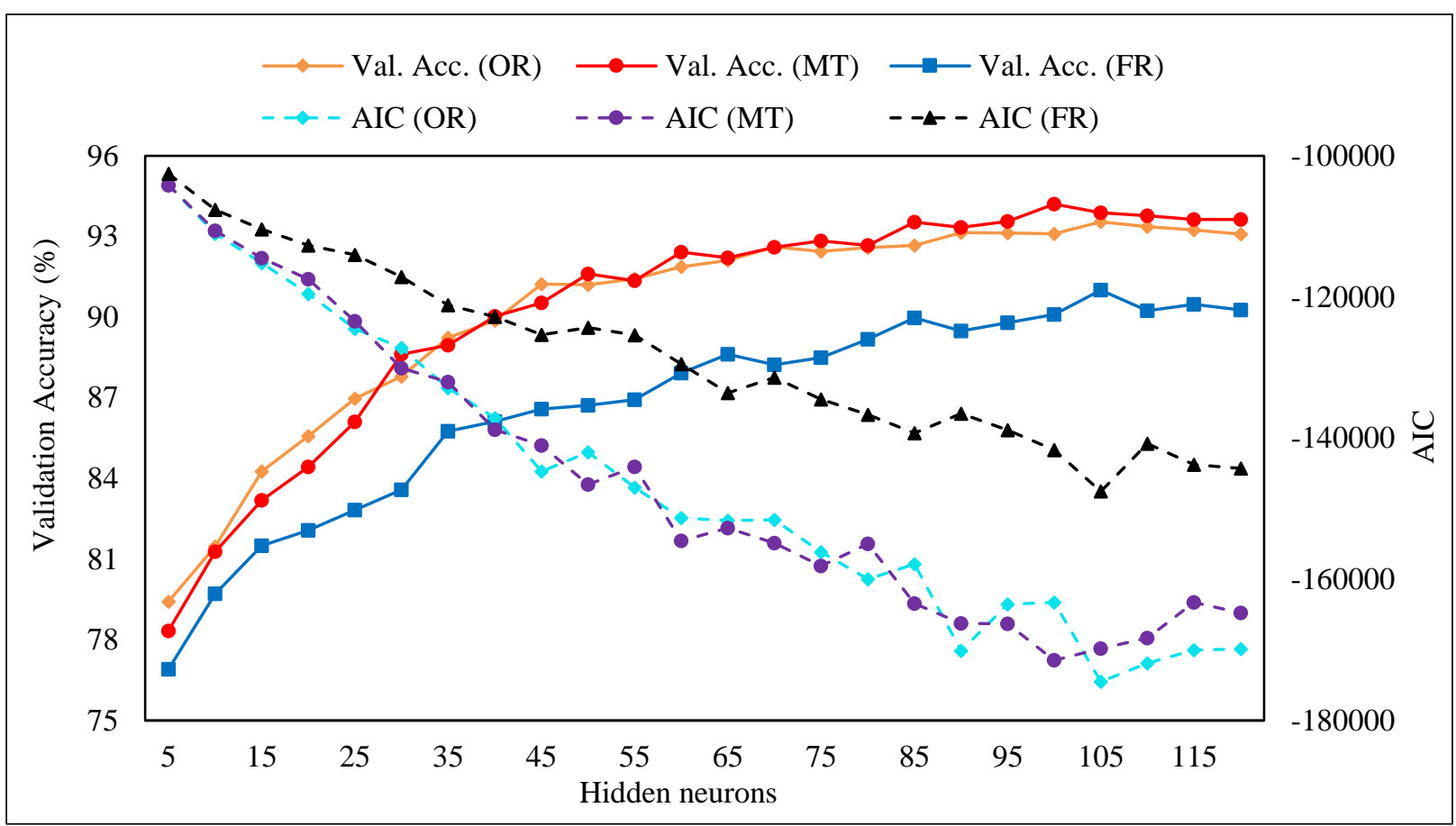

Figure 5. The validation accuracies and AIC with respect to hidden neurons of three data (without pre-processing)

The results obtained by the MLP model with Mean-SD normalizations with PCA technique of three data configurations are shown in Figure 6(a). It is clearly shown that the validation and AUC of ROC accuracies of Mean-SD normalization with PCA of MT data configuration are higher than the FR and OR data configurations. The FR data configuration is not in good agreement with others and hence shows the lowest validation and AUC of ROC accuracies. The maximum validation and AUC of ROC accuracy, which is $94.78 \%$ and $96.72 \%$, are achieved at 100 hidden neuron numbers of MT data configuration, where the AIC also shows the most negligible value. The other two configurations have the least values of AIC at 105 hidden neuron numbers.

Figure 6(b) displays the results of the Min-Max normalization with PCA scheme of three data configurations. It is observed that the maximum validation and AUC accuracies of MT data configurations are $94.54 \%$ and $96.38 \%$ respectively. These accuracies are acquired at 105 hidden neuron numbers, whereas the validation and AUC accuracy of OR $(94.31 \%$ and 96.13\%) and FR (90.92\% and 93.60\%) configurations are at 105 and 110 hidden neurons, respectively. Similarly, the MT data configuration with Min-Max + PCA scheme gives the best results than other configurations. The FR configuration achieves lower accuracies compared to OR and MT configurations. 
Ilyas Ahmad Huqqani et al. / Geosfera Indonesia 6 (1), 2021, 20-39
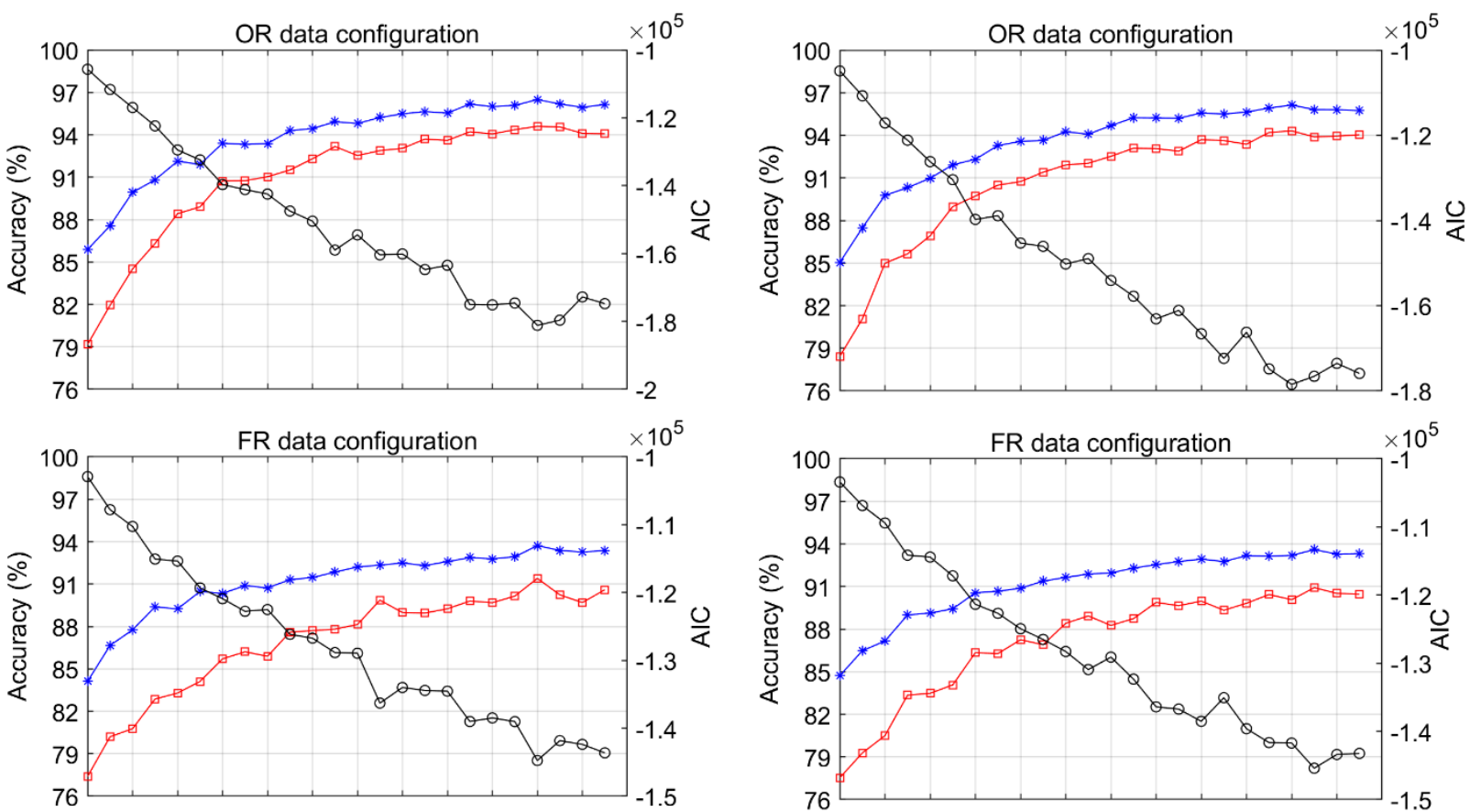

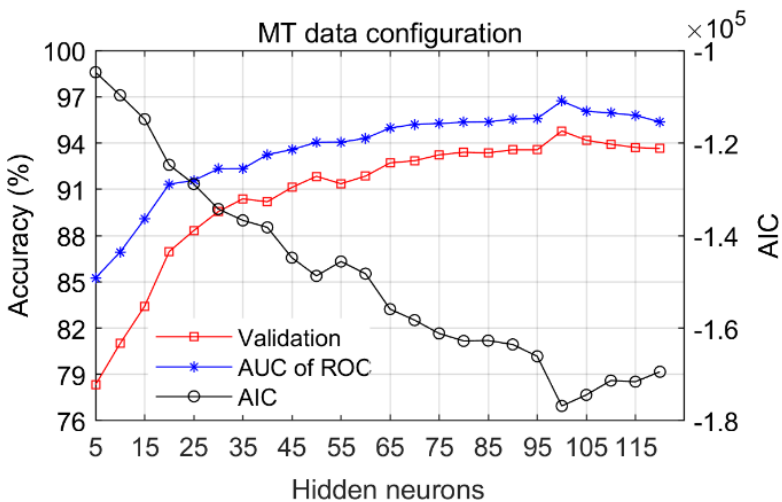

(a)

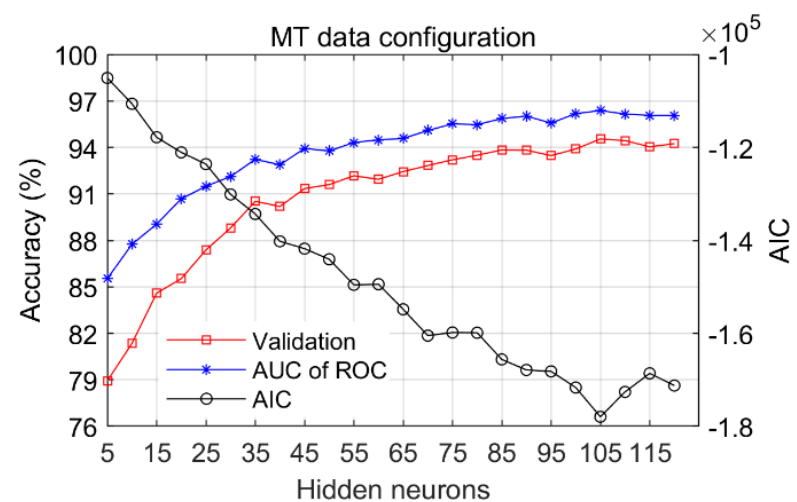

(b)

Figure 6. The accuracies and AIC of three data configurations (a) Mean-SD with PCA scheme (b) Min-Max with PCA scheme

It is also observed that the Mean-SD with PCA scheme performs better than the MinMax with PCA scheme. The Mean-SD + PCA scheme of MT data configuration stables and converges at the lowest number of hidden neurons, i.e., 100, and also gives better results than the FR and OR configurations, as well as the Min-Max + PCA scheme of MT, FR, and OR configurations. In Min-Max with PCA scheme, the OR, MT, and FR configurations converge at 105, 105, and 110 number of hidden neurons, respectively; therefore, this scheme is more complex, which degrades the generalization of the MLP model. The FR data configuration indicates lower accuracies for both schemes.

Finally, the study area's entire data is applied to the trained MLP model to obtain the LHI. This LHI is used to generate the landslide hazard maps. It is split into four main classes, i.e., highly hazardous area, hazardous, moderately hazardous area, and non-hazardous area. The 'highly hazardous area' class belongs to the most vulnerable area to landslide and $10 \%$ 
of the maximum LHI values (90-100\%). The 'hazardous' class is also associated with the more landslide-prone region, and the values are the next $10 \%$ of LHI values (80-90\%). The third class is the 'moderately hazardous area', which relates to the following $20 \%$ of LHI (60$80 \%$ ), and the fourth 'non-hazardous area' class is for the remaining $60 \%$ of LHI values (0$60 \%$ ). The resulting landslide hazard maps of the study area produced using Mean-SD with PCA and Min-Max with PCA schemes of MT data configurations at 100 and 105 hidden neurons are shown in Figure 7(a) and (b), respectively.

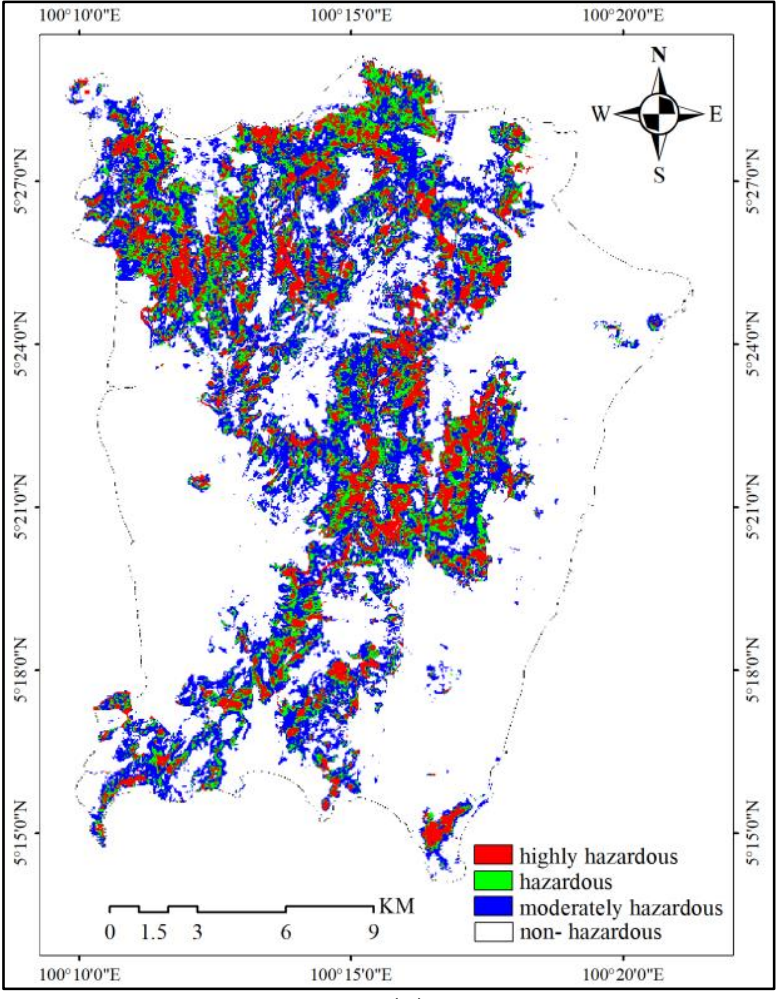

(a)

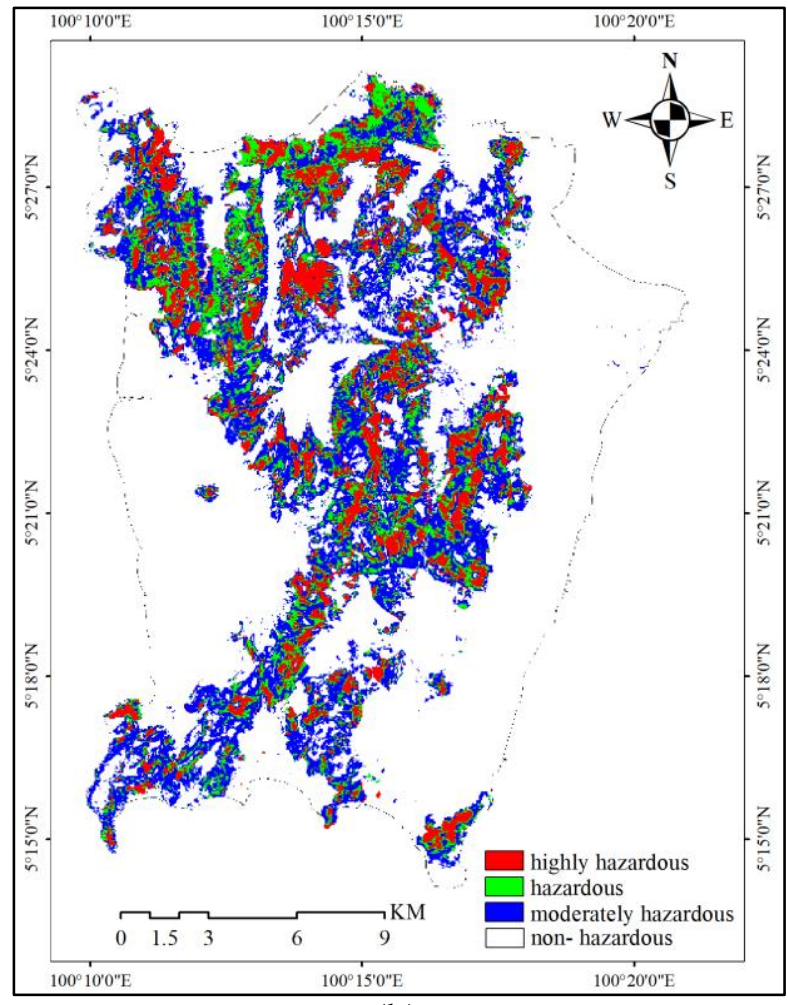

(b)

Figure 7. Landslide hazard maps of MT data configuration with (a) Mean-SD and PCA (b) Min-Max and PCA

The present study implements the advanced intelligence technique (ANN based MLP model) using different configurations of landslide causative factors to map landslide hazards in Penang Island, Malaysia. Several statistical metrics such as accuracy, AIC, AUC, TRP, FRP and RMSE have been utilized by many researchers in order to evaluate the model's performance (Nhu et al., 2020; Tien Bui et al., 2020). The results obtained from the MLP model of AUC of ROC are compared with other related studies as shown in Table 1. 
Table 1. Comparison of results of MLP model with other related studies

\begin{tabular}{lcc}
\hline \multicolumn{1}{c}{ References } & AUC (\%) & Data Configuration \\
\hline Bui et al., 2018 & 87.50 & Time series \\
de Oliveira et al., 2019 & 92.25 & OR \\
D. T. Bui et al., 2020 & 87.25 & FR \\
Sahana et al., 2020 & 83.60 & FR \\
Nhu et al., 2020 & 86.60 & FR \\
Abbaszadeh Shahri et al., 2019 & 80.10 & FR \\
Present study & 96.72 & MT \\
\hline
\end{tabular}

The MLP model contains one hidden layer between input and output layers and its hidden neurons play a vital role in predicting the landslide hazards. Besides, MT data configuration has an advantage to acquire better accuracy at lower number of hidden neurons. It is, therefore, observed that the performance of MLP model of present study shows higher AUC than the others.

\section{Conclusion}

The MT data configuration produces good validation accuracy at a lower number of hidden neurons than OR and FR data configurations, with and without pre-processing. The MT data configuration represents more meaningful information for the MLP to interpret than the other two data configurations. Pre-processing with normalization techniques and PCA improves the performance of the output. The best AUC of ROC of both Mean-SD and MinMax with PCA schemes are $96.72 \%$ and $96.38 \%$, respectively. The MT data configuration with Mean-SD normalization with PCA scheme gives the best results with good accuracies, as well as a smaller number of hidden neurons. The Mean-SD with PCA scheme shows the smaller complexity of the MLP model with a smaller number of hidden neurons. Therefore, MT data configuration with the Mean-SD normalization and PCA scheme is more robust and stable in the MLP model's training for landslide prediction.

\section{Acknowledgments}

The author would like to thank Malaysia Education Ministry/Kementerian Pendidikan Malaysia (KPM) for providing the financial support under research grant (FRGS - Geran Penyelidikan Fundamental 203/PELECT/6071390) in this project.

\section{Conflict of interest}

The authors declare no conflict of interest. 


\section{References}

Akaike, H. (1974). A New Look at the Statistical Model Identification. IEEE Transactions on Automatic Control, 19(6), 716-723. https://doi.org/10.1109/TAC.1974.1100705.

Alkhasawneh, M. S., Ngah, U. K., Tay, L. T., \& Isa, N. A. M. (2014). Determination of importance for comprehensive topographic factors on landslide hazard mapping using artificial neural network. Environmental Earth Sciences, 72(3), 787-799. https://doi.org/10.1007/s12665-013-3003-x.

Alkhasawneh, M. S., Ngah, U. K., Tay, L. T., Mat Isa, N. A., \& Al-Batah, M. S. (2013). Determination of important topographic factors for landslide mapping analysis using MLP network. The Scientific World Journal, 2013(415023), 1-12. https://doi.org/10.1155/2013/415023.

Begueria, S. (2006). Validation and Evaluation of Predictive Models in Hazard Assessment and Risk Management. Natural Hazards, 37(3), 315-329. https://doi.org/10.1007/s11069-005-5182-6.

Bui, D. T., Tsangaratos, P., Nguyen, V. T., Liem, N. V., \& Trinh, P. T. (2020). Comparing the prediction performance of a Deep Learning Neural Network model with conventional machine learning models in landslide susceptibility assessment. Catena, 188(C), 104426. https://doi.org/10.1016/j.catena.2019.104426.

Bui, K. T. T., Tien Bui, D., Zou, J., Van Doan, C., \& Revhaug, I. (2018). A novel hybrid artificial intelligent approach based on neural fuzzy inference model and particle swarm optimization for horizontal displacement modeling of hydropower dam. Neural Computing and Applications, 29(12), 1495-1506. https://doi.org/10.1007/s00521-0162666-0.

Catani, F., Lagomarsino, D., Segoni, S., \& Tofani, V. (2013). Landslide susceptibility estimation by random forests technique: Sensitivity and scaling issues. Natural Hazards and Earth System Sciences, 13(11), 2815-2831. https://doi.org/10.5194/nhess-13-28152013.

Chen, W., Fan, L., Li, C., \& Pham, B. T. (2020). Spatial prediction of landslides using hybrid integration of artificial intelligence algorithms with frequency ratio and index of entropy in Nanzheng county, China. Applied Sciences (Basel), 10(1), 29. https://doi.org/10.3390/app10010029.

Chung, C. J. F., \& Fabbri, A. G (1999). Probabilistic prediction models for landslide hazard mapping. Photogrammetric Engineering and Remote Sensing, 65(12), 1389-1399.

Cousineau, D., \& Allan, T. (2015). Likelihood and its use in Parameter Estimation and Model Comparison. Mesure et Évaluation En Éducation, 37(3), 63-98. https://doi.org/10.7202/1036328ar.

Cruden, D. M. (1991). A simple definition of a landslide. Bulletin of the International Association of Engineering Geology - Bulletin de l'Association Internationale de Géologie de l'Ingénieur, 43(1), 27-29. 
de Oliveira, G. G., Ruiz, L. F. C., Guasselli, L. A., \& Haetinger, C. (2019). Random forest and artificial neural networks in landslide susceptibility modeling: a case study of the Fão River Basin, Southern Brazil. Natural Hazards, 99(2), 1049-1073. https://doi.org/10.1007/s11069-019-03795-x.

De Souto, M. C. P., De Araujo, D. S. A., Costa, I. G., Soares, R. G. F., Ludermir, T. B., \& Schliep, A. (2008). Comparative study on normalization procedures for cluster analysis of gene expression datasets. 2008 IEEE International Joint Conference on Neural Networks (IEEE World Congress on Computational Intelligence), 2792-2798. https://doi.org/10.1109/IJCNN.2008.4634191.

Garrett, J. H. (1994). Where and Why Artificial Neural Networks Are Applicable in Civil Engineering. Journal of Computing in Civil Engineering, 8(2), 129-130.

Gian Quoc, A., Duc-Tan, T., Nguyen Dinh, C., \& Tien Bui, D. (2018). Flexible configuration of wireless sensor network for monitoring of rainfall-induced landslide. Indonesian Journal of Electrical Engineering and Computer Science, 12(3), 1030-1036. https://doi.org/10.11591/ijeecs.v12.i3.pp1030-1036.

Guzzetti, F., Carrara, A., Cardinali, M., \& Reichenbach, P. (1999). Landslide hazard evaluation: A review of current techniques and their application in a multi-scale study, Central Italy. Geomorphology (Amsterdam), 31(1-4), 181-216.

Guzzetti, F., Mondini, A. C., Cardinali, M., Fiorucci, F., Santangelo, M., \& Chang, K. T. (2012). Landslide inventory maps: New tools for an old problem. Earth - Science Reviews, 112(112), 42-66. https://doi.org/10.1016/j.earscirev.2012.02.001.

Haykin, S., \& Lippmann, R. (1994). Neural networks, a comprehensive foundation. International journal of neural systems, 5(4), 363-364.

Huqqani, I. A., Tay, L. T., \& Saleh, J. M. (2019). Analysis of landslide hazard mapping of Penang island Malaysia using bivariate statistical methods. Indonesian Journal of Electrical Engineering and Computer Science, 16(2), 781-786. https://doi.org/10.11591/ijeecs.v16.i2.pp781-786.

Husin, N. A., Salim, N., \& Ahmad, A. R. (2008). Modeling of dengue outbreak prediction in Malaysia: A comparison of neural network and nonlinear regression model. 2008 International Symposium on Information Technology, 1-4. https://doi.org/10.1109/ITSIM.2008.4632022.

Hutchinson, J. N. (1995). Landslide Hazard Assessment. Keynote Paper. In: Bell, D.H., Ed., Landslides. 6th International Symposium on Landslides, 1805-1841.

Kaur, N., \& Kumar, K. (2016). Normalization Based K-means Data Analysis Algorithm. International Journal of Advanced Research in Computer Science and Software Engineering, ISSN, 2277, 455-457.

Kawabata, D., \& Bandibas, J. (2009). Landslide susceptibility mapping using geological data, a DEM from ASTER images and an Artificial Neural Network (ANN). Geomorphology (Amsterdam), 113(1-2), 97-109. https://doi.org/10.1016/j.geomorph.2009.06.006. 
Kotsiantis, S. B., Kanellopoulos, D., \& Pintelas, P. E. (2006). Data Preprocessing for Supervised Learning. International Journal of Computer Science, 1, 111-117.

Lee, D. H., Kim, Y. T., \& Lee, S. R. (2020). Shallow landslide susceptibility models based on artificial neural networks considering the factor selection method and various non-linear activation functions. Remote Sensing, 12(7), 1194. https://doi.org/10.3390/rs12071194.

Lee, S., \& Talib, J. A. (2005). Probabilistic landslide susceptibility and factor effect analysis. Environmental Earth Sciences, 47(7), 982-990. https://doi.org/10.1007/s00254-0051228-z.

Liu, L., Li, S., Li, X., Jiang, Y., Wei, W., Wang, Z., \& Bai, Y. (2019). An integrated approach for landslide susceptibility mapping by considering spatial correlation and fractal distribution of clustered landslide data. Landslides, 16(4), 715-728. https://doi.org/10.1007/s10346-018-01122-2.

Lombardo, L., \& Mai, P. M. (2018). Presenting logistic regression-based landslide susceptibility results. Engineering Geology, 244(C), 14-24. https://doi.org/10.1016/j.enggeo.2018.07.019.

Murakami, S., Tien, T. L., Omar, R. B. C., Nishigaya, T., Aziza, N., Roslan, R., ... \& Sakai, N. (2014). Landslides Hazard map in Malay peninsula by using historical landslide database and related information. J Civil Eng Res, 4(3A), 54-58.

Nhu, V. H., Shirzadi, A., Shahabi, H., Singh, S. K., Al-Ansari, N., Clague, J. J., ... Ahmad, B. B. (2020). Shallow landslide susceptibility mapping: A comparison between logistic model tree, logistic regression, naïve bayes tree, artificial neural network, and support vector machine algorithms. International Journal of Environmental Research and Public Health, 17(8), 1-30. https://doi.org/10.3390/ijerph17082749.

Ortiz, J. A. V., \& Martínez-Graña, A. M. (2018). A neural network model applied to landslide susceptibility analysis (Capitanejo, Colombia). Geomatics, Natural Hazards and Risk, 9(1), 1106-1128. https://doi.org/10.1080/19475705.2018.1513083.

Panchal, G., Ganatra, A., Kosta, Y. P., \& Panchal, D. (2010). Searching most efficient neural network architecture using Akaike's information criterion (AIC). International Journal of Computer Applications, 1(5), 41-44.

Paola, J. D., \& Schowengerdt, R. A. (1995). A review and analysis of backpropagation neural networks for classification of remotely-sensed multi-spectral imagery. International Journal of Remote Sensing, 16(16), 3033-3058. https://doi.org/10.1080/01431169508954607.

Pradhan, B., \& Lee, S. (2010). Delineation of landslide hazard areas on Penang Island, Malaysia, by using frequency ratio, logistic regression, and artificial neural network models. Environmental Earth Sciences, 60(5), 1037-1054. https://doi.org/10.1007/s12665-009-0245-8.

Regmi, A. D., Devkota, K. C., Yoshida, K., Pradhan, B., Pourghasemi, H. R., Kumamoto, T., \& Akgun, A. (2014). Application of frequency ratio, statistical index, and weights-of- 
evidence models and their comparison in landslide susceptibility mapping in Central Nepal Himalaya. Arabian Journal of Geosciences, 7(2), 725-742. https://doi.org/10.1007/s12517-012-0807-z.

Sahana, M., Pham, B. T., Shukla, M., Costache, R., Thu, D. X., Chakrabortty, R., ... Prakash, I. (2020). Rainfall induced landslide susceptibility mapping using novel hybrid soft computing methods based on multi-layer perceptron neural network classifier. Geocarto International, 1-25. https://doi.org/10.1080/10106049.2020.1837262.

Scaioni, M., Longoni, L., Melillo, V., \& Papini, M. (2014). Remote sensing for landslide investigations: An overview of recent achievements and perspectives. Remote Sensing, 6(10), 9600-9652. https://doi.org/10.3390/rs6109600.

Shahri, A. S., Spross, J., Johansson, F., \& Larsson, S. (2019). Landslide susceptibility hazard map in southwest Sweden using artificial neural network. Catena, 183(C), 104225. https://doi.org/10.1016/j.catena.2019.104225.

Sheela, K. G., \& Deepa, S. N. (2013). Review on methods to fix number of hidden neurons in neural networks. Mathematical Problems in Engineering, 2013, 1-11. https://doi.org/10.1155/2013/425740.

Sun, X., Chen, J., Bao, Y., Han, X., Zhan, J., \& Peng, W. (2018). Landslide susceptibility mapping using logistic regression analysis along the Jinsha river and its tributaries close to Derong and Deqin County, southwestern China. ISPRS International Journal of GeoInformation, 7(11), 438. https://doi.org/10.3390/ijgi7110438.

Tay, L. T., Alkhasawneh, M. S., Ngah, U. K., \& Lateh, H. (2014). Landslide hazard mapping of Penang Island using dominant factors. 2014 IEEE 2nd International Symposium on Telecommunication Technologies $\quad$ (ISTT), $154-158$. https://doi.org/10.1109/ISTT.2014.7238195.

Tien Bui, D., Hoang, N. D., Martínez-Álvarez, F., Ngo, P. T. T., Hoa, P. V., Pham, T. D., ... Costache, R. (2020). A novel deep learning neural network approach for predicting flash flood susceptibility: A case study at a high frequency tropical storm area. Science of the Total Environment, 701(C), 134413. https://doi.org/10.1016/j.scitotenv.2019.134413.

Van Westen, C. J., Rengers, N., \& Soeters, R. (2003). Use of geomorphological information in indirect landslide susceptibility assessment. Natural Hazards, 30(3), 399-419. https://doi.org/10.1023/B:NHAZ.0000007097.42735.9e.

Van Westen, C. J. (1993). Application of geographic information systems to landslide hazard zonation. International Institute for Geo-Information Science and Earth Observation. http://www.itc.nl/library/Papers_1993/phd/vanwesten.pdf.

Varnes, D. (1984). Landslide hazard zonation: A review of principles and practice. Natural Hazards, (3) .

Ya'acob, N., Tajudin, N., \& Azize, A. M. (2019). Rainfall-landslide early warning system (RLEWS) using TRMM precipitation estimates. Indonesian Journal of Electrical Engineering and Computer Science, 13(3), 1259-1266. https://doi.org/10.11591/ijeecs.v13.i3.pp1259-1266. 